\title{
Circadian clocks - from genes to complex behaviour
}

\author{
Till Roenneberg*, Martha Merrow \\ Institute for Medical Psychology, Ludwig Maximilians University, \\ Goethestr. 31-33, 80336 Munich, Germany
}

(Received 4 February 1999; accepted 16 April 1999)

\begin{abstract}
Circadian clocks control temporal structure in practically all organisms and on all levels of biology, from gene expression to complex behaviour and cognition. Over the last decades, research has begun to unravel the physiological and, more recently, molecular mechanisms that underlie this endogenous temporal programme. The generation of circadian rhythms can be explained, at the molecular level, by a model based upon a set of genes and their products which form an autoregulating negative feedback loop. The elements contributing to this transcriptional feedback appear to be conserved from insects to mammals. Here, we summarize the process of the genetic and molecular research that led to 'closing the molecular loop'. Now that the reductionist approach has led to the description of a detailed clock model at the molecular level, further insights into the circadian system can be provided by combining the extensive knowledge gained from decades of physiological research with molecular tools, thereby reconstructing the clock within the organism and its environment. We describe experiments combining old and new tools and show that they constitute a powerful approach to understanding the mechanisms that lead to temporal structure in complex behaviour. (C) Inra/Elsevier, Paris
\end{abstract}

circadian rhythm / transcription / entrainment / clock gene / autoregulating negative feedback

Résumé - Les horloges circadiennes - depuis les gènes jusqu'aux comportements les plus complexes. Les horloges circadiennes contrôlent l'organisation du temps chez pratiquement tous les organismes et à tous les niveaux de la biologie, depuis l'expression des gènes jusqu'aux comportements les plus complexes et à la cognition. Au cours des dernières décennies, la recherche a commencé à dévoiler les mécanismes physiologiques et moléculaires sous-jacents à ce programme temporel endogène. L'origine des rythmes circadiens peut être expliquée, au niveau moléculaire, par une série de gènes et leurs produits, qui forment une boucle de rétroaction négative autorégulée. Les éléments qui contribuent à cette rétroaction transcriptionnelle apparaissent conservés depuis les insectes jusqu'aux mammifères. Nous avons résumé ici les résultats les plus récents des recherches génétiques et moléculaires qui conduisent à « refermer la bouche moléculaire ». Alors que l'approche réductionniste a conduit à la description d'un modèle détaillé d'horloge au niveau moléculaire, une vision plus perspicace des systèmes circadiens peut être effectuée en combinant les connaissances très étendues obtenues depuis plusieurs décades de recherche en physiologie, avec les outils molécu-

* Correspondence and reprints

E-mail: till.roenneberg@imp.med.uni-muenchen.de 
laires, ce qui permet une reconstruction de l'horloge à l'intérieur de l'organisme placé dans son environnement. Nous décrivons des expériences qui combinent des outils anciens et nouveaux et qui montrent qu'ils constituent une approche puissante afin de comprendre les mécanismes qui conduisent à une organisation temporelle des comportements les plus complexes. C Inra/Elsevier, Paris

rythme / transcription / entraînement / gène clock / boucle d'autorégulation

\section{INTRODUCTION}

One of the most fascinating questions in biology concerns the mechanisms by which organisms direct metabolism quasi independently of astronomical time. These temporal programmes are controlled by biological clocks that reflect the four temporal 'spaces' governing life on our planet (tides, day, lunar cycle and year). Among these, the circadian system has been investigated most intensively, and we are beginning to understand how a circa-24-h rhythmicity is generated.

In his classic paper that appeared in the proceedings of the first dedicated international conference on biological clocks in Cold Spring Harbor, Colin Pittendrigh defined circadian systems by their unique properties [76]. These properties have been a guideline ever since to describe, dissect and to model circadian systems in organisms of all phyla. The change in models over the past decades reflects both fresh insights and the development of experimental tools. Methods open new possibilities, shape the approach to the overlying questions, and thus, have an impact on how explanations are found. In the 1960 s and 1970 s, biochemical methods allowed the dissection of cellular metabolism, and cybernetics provided formal tools for the description of complex systems. Accordingly, the models describing the mechanisms underlying circadian rhythmicity, involved a cybernetic view of cellular metabolism [25]. With the advent of molecular tools, circadian models centred around gene regulation.

The mechanisms underlying circadian rhythmicity are implemented, in all organ- isms, at the cellular level. Even at this level - for example in unicellular organisms circadian systems have to cope with a temporal environment influencing metabolism. Not only does the external environment have an impact, but so do endogenous states, such as energy charge or nutrient stores, which are modified regularly over time. Like unicells, individual cells of multicellular organisms (e.g. pacemaker neurons) may also contain all the elements of a circadian system (input $\rightarrow$ oscillator $\rightarrow$ output): receptors, intracellular signal transduction, a machinery that generates the rhythm and outputs (e.g. rhythmic electric activity). These cell clocks are entrained by a temporally structured micro-environment, involving transmitters, hormones or other chemical signals [12]. Some of these cells (e.g. in the retina and the pineal) respond directly to exogenous signals (zeitgeber) such as light $[15,75]$.

The descriptions established in the premolecular era provided us with the basic concepts that are unique to intact circadian systems [9] and have served as the basis for all subsequent genetic and molecular research. They, for example, help us to distinguish between rhythms that are merely driven by environmental changes and those that respond actively through the robustness of an ongoing endogenous circadian oscillator. They, however, describe the contents of a Pandora's box: i) a feedback loop producing rhythmicity (independent of its frequency); ii) the circadian range of the period; iii) an amplitude sufficiently robust to drive output rhythms; iv) the fact that the rhythmicity is sufficiently self-sustained to con- 
tinue unabated; v) temperature compensation; and vi) entrainability [90]. Now, that the box is being opened by molecular circadian biology, the generalized features of a clock producing the known circadian phenotype may turn out to be a sum of qualities, each implemented by different cellular functions.

Neither rhythmicity nor autoregulating feedback are exclusive to elements of the oscillator but may also be inherent in inputs and outputs $[26,91]$. The discovery of genes that affect circadian properties when mutated is currently progressing with breathtaking speed. All of these can be regarded as important elements within the complex circadian
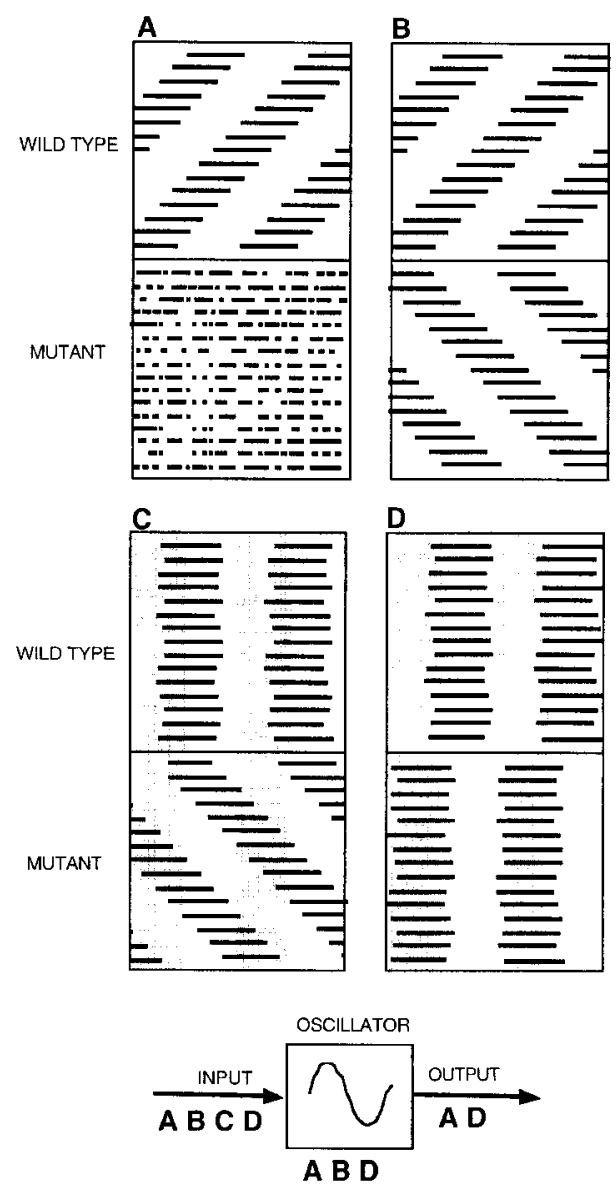

system. A future task is to determine the function of these clock elements and their 'location' within the system. Figure 1 summarizes schematically the circadian phenotypes that can result from mutations of clock genes and indicates their possible location within the circadian system.

\section{DISCOVERING THE COGS OF THE CIRCADIAN CLOCK}

\subsection{The search for circadian genes}

First attempts to identify circadian clock genes used the unicellular alga Chlamydomonas [14], the fungus Neurospora [27] and the fruit fly Drosophila [50] as classic model organisms for genetic research. They resulted in the identification of several mutant strains - mainly with altered circadian periods in constant conditions. Among these, the period gene (per) in Drosophila and the frequency gene $(f r q)$ in Neurospora were the first to be cloned $[13,66,83]$.

Figure 1. Possible phenotypic changes due to mutations of clock genes and their possible location within the circadian pathway (bottom diagram). Each panel shows examples for a wild type (top) and a mutant (bottom). A) Arhythmicity could be produced by either a mutation in the oscillator, in the output (with the clock still running), or in the input (e.g. mimicking constant bright light). B) Period changes could be due to a mutation in the oscillator (e.g. changing the rates of production, phosphorylation, degradation, etc.) or in the input (inputs are not necessarily just 'passive' signal transducers, only 'working' with external signals; such a mutation could mimic different light fluences which is known to influence period). C) 'Blindness' can only be caused by a mutation in the light input (with the clock still entrainable by non-photic zeitgebers; it free-runs in light/dark cycles, provided activity is not directly light-affected and does not feed back to the clock). D) Different phase angles in entrainment would be produced either by mutations as exemplified in B, or by mutation in an output that is itself a 'slave' oscillator determining the specific phase of a rhythm. 
While the search for circadian mutants in Chlamydomonas, Neurospora and Drosophila was based on mutagenesis and subsequent screening for stable and heritable period changes, the first step into mammalian circadian genetics was fortuitous. A normal hamster shipment contained an individual male (the tau mutant) that displayed a significantly shorter period than any hamster previously recorded [82]. Subsequent mutagenesis and screening were initiated in the superior genetic model system, the mouse, and resulted in the identification of a gene (clock) that lengthens the circadian period [114].

The finding that prokaryotes (Synechococcus) also co-ordinated their daily metabolism with the help of an endogenous temporal programme [110] toppled the dogma that circadian clocks were unique to eukaryotes [76]. For purposes of isolating clock genes, cyanobacteria offer several advantages. The generation time is short and the number of individual organisms available for mutagenesis and screening is by orders of magnitude - larger than in any of the other model systems; recording of circadian rhythmicity was made very simple with the help of a luciferase reporter gene construct; and finally, automation enables the screening of thousands of individual cells (or rather their colonies) concurrently. With these tools, mutants were identified with decreased amplitudes, bimodal structure and altered periods in circadian rhythmicity [49].

For the mutant search in Synechococcus, the open reading frame of the bacterial luciferase gene was fused with a clock-controlled promoter ( $p s b A I$, a photosystem II gene). This construct reports circadian rhythmicity by emitting light when the fusion gene is expressed. Similarly, in Arabidopsis, the firefly luciferase gene was fused with a rhythmically expressed promoter involved in photosynthesis ( $c a b 2$, chlorophyll $\mathrm{a} / \mathrm{b}$ binding protein). The transformants were mutagenized, and short and long period mutants were obtained, as well as one with reduced amplitude $[69,106]$. Bioluminescent reporter constructs were later also used for Drosophila (see below).

The identification of a genetic mutation resulting in altered circadian qualities, (e.g. period length), is by itself not enough to conclude that this gene is centrally involved in circadian rhythmicity (see also figure 1). Many cellular functions must be involved in circadian rhythmicity: transcription, translation, protein modification, RNA and protein degradation, energy metabolism, and elements transducing zeitgeber signals to the clock. There are good examples showing that altered circadian properties can be due to mutants affecting other cellular functions. The mutation of a gene encoding a neuronal cell adhesion molecule ( ncam- 1 ) results in a phenotype similar to the clock mutation in mice [103]. Neurospora mutants defective in lipid metabolism (chol-1 and $c e l$ ) have extremely long periods (up to $70 \mathrm{~h}$ ) and indicate complicated interactions with frq (as shown with double mutants) [51]. Finally, biochemical experiments in algae show that circadian rhythmicity can be influenced by photosynthesis, as well as by peroxisomal and nitrate metabolism [86, 91]. Although these effects appear to be non-specific, without the information as to how these genes and metabolic functions affect circadian properties, our understanding of the system remains incomplete.

In view of the numerous ways that circadian properties can be affected, it is surprising that relatively few clock genes were originally identified in the genetic screens. The majority of alleles originally isolated in Drosophila and Neurospora mapped to per and frq, respectively, giving rise to the optimism that few genes are involved in the generation of circadian rhythmicity. Thirteen years after per was identified, a mutant screen in Drosophila revealed another clock gene, timeless (tim), conferring short or long periods as well as arhythmicity [100]. 


\subsection{Building a simple molecular clock}

Demonstration that a gene and its products are directly responsible for the molecular generation of the circa-24-h rhythmicity has been based on a set of five criteria which were first formulated 20 years ago and have been marginally modified since [7] (for additional references, see [90]). 1) Mutations in a clock component should affect canonical clock properties and null mutations should abolish normal rhythmicity. 2) The amount (activity) of the component must oscillate in a self-sustained manner with an appropriate periodicity. 3) Induced changes in the amount (activity) of the component must (by feedback) act to change the amount (activity) of the component. 4) The phase of the component's oscillation must be reset by shifts in the light/dark growth regimen, and conversely, the overt rhythm must be reset by changes in the amount (activity) of the component. 5) Prevention of the component's oscillation should result in loss of the overt rhythm. In particular, there should be no degree of constitutive expression that will support rhythmicity. These criteria basically describe the behaviour of an element involved in an autoregulating negative feedback loop that constitutes the circadian oscillator, i.e. a molecule that is rhythmic with the same periodicity as the observed circadian outputs, which affects its own oscillation via feedback, and which responds to zeitgeber signals. A machinery generating rhythmicity has to involve negative feedback; this has long been known from modelling oscillations mathematically (for references, see [90]).

Are these criteria fulfilled for per and frq? Null mutants are arhythmic $[22,116]$ and in free-running conditions mRNA and protein levels oscillate rhythmically [23, 30]. Innovative experiments with inducible or constitutive promoters (rhodopsin and heat shock promoters in Drosophila and the quinic acid inducible qa-2 promoter in $\mathrm{Neu}$ rospora) allowed the remaining questions to be experimentally addressed. Both per and $f r q$ participate in a negative feedback loop $[7,34,117]$. Discrete induction results in a stable phase shift of the overt rhythm [7, 24], and conversely, zeitgebers can induce changes in the phase of the molecular oscillation of per and frq [18, 52, 58]. Constitutive expression results in arhythmicity $[7,117]$.

As a result of the experiments in Drosophila and Neurospora the first molecular clock model was constructed, a model that had been proposed several years before based on the fact that per mRNA was constitutively expressed in the per null mutant [34]. The clock gene (per or frq) produces a protein that in turn inhibits the transcription of its mRNA. Due to RNA and protein degradation, the self-inhibitory effect is eventually relieved and the cycle starts again.

\subsection{A matter of details}

Once the basic molecular models were constructed and the criteria fulfilled for per and frq, several questions had to be answered concerning the detailed progression of the loop. Which processes are responsible for the long time constant in the circadian range? How much does de novo transcription and how much does turnover of RNA and proteins contribute to the oscillation? What are the details of inhibition and activation? How is the loop affected by zeitgeber signals (see section 2.5)? The hard work of molecular biochemistry began to fill in the details about the progression of this autoregulating negative feedback loop.

\subsubsection{The circadian time range}

Both PER [23] and FRQ [30] are phosphorylated in a time-dependent manner. This progressive phosphorylation, together with the lag of $4-6 \mathrm{~h}$ between mRNA and protein peaks $[30,65]$, are thought to be responsible for the circadian time range generated 
by the feedback loop. Strong support for the phosphorylation hypothesis came with the discovery of a new clock gene. Various alleles of doubletime ( $\mathrm{dbt}$ ) produce phenotypes similar to per and tim mutants; $d b t$ is, however, different in two important qualities. Unlike in the former two genes, the mRNA is not rhythmic (though DBT is essential for rhythmicity) and null mutations are lethal $[47,80]$. DBT is a casein kinase I homologue [80] and is responsible for the phosphorylation of PER. Gene dosage studies indicate that $d b t$ function negatively correlates with period [116]; thus, phosphorylation contributes to the circadian period length.

\subsubsection{Transcription and turnover}

Theoretically, the degradation kinetics of mRNA and protein are crucial i) for the system to oscillate, ii) for it not to damp, and iii) for the length of the period. So far, little is known about the degradation kinetics in the different model systems. A timeof-day-specific, i.e. cyclic, degradation has been suggested for per mRNA [21]. Results also strongly suggested that the rhythm in mRNA levels (of per, tim and frq) are due to changing transcription rates, rather than due to controlled degradation. Recently, nuclear run-on experiments were able to correlate per and tim rhythmicity with de novo transcription [105]; yet, per cycling is not only controlled at the transcriptional level [16, $29,105]$.

\subsubsection{The inhibiting process}

From the 'simple' molecular clock model, the role of PER as an inhibitory element was known but what was the role of TIM in this negative feedback? tim was discovered independently by two approaches once by mutagenesis, as described above, and once in a search for protein partners binding to PER (using the two-hybrid system) [31]. Subsequent experiments showed that per and tim oscillations are interdepen- dent, and that PER and TIM form a complex (thereby stabilizing monomers) which is necessary for both proteins to enter the nucleus [116]. It became clear that both contributed to the negative feedback.

\subsubsection{The activating process}

After clock was cloned in the mouse [6, 46], a search for partners of the CLOCK protein began. The rationale for this search [32] was based on the following results: i) analysis of the Drosophila per-promoter revealed a short enhancing sequence (E-box, CACGTG) that was responsible for the robust rhythmic transcription of per [33]; ii) basic-helix-loop-helix (bHLH) transcription factors are known to bind to E-boxes, but only when they form heterodimers with a partner protein; and iii) CLOCK itself contains a bHLH motif [32]. Using the two-hybrid system, a protein binding to CLOCK was found and its gene was cloned. By sequence homology, it was identified as bmall (brain and muscle arnt-like protein 1) [32, 43], an isoform of the independently cloned mop3 (members of the PAS superfamily) [38]. These discoveries finally 'closed the circadian loop' $[19,32]$ predicted 8 years before. Two recently identified clock mutants in Drosophila, cycle and jerk, turned out to be homologues of bmall and clock, respectively [5, 93]. They also bind as heterodimers to the E-box of the Drosophila per promoter [19], thereby activating per transcription. Experiments using promoters of Drosophila per and tim as well as of mouse per1, showed that binding of the CLOCK/BMAL1 heterodimer is necessary as the activating element for per and tim RNA rhythmicity $[19,32]$, while interactions of PER/TIM heterodimers with CLOCK/BMAL1 are inhibitory.

Within a few years, the missing elements of the 'simple' molecular clock model had been discovered and numerous homologues were found indicating that the molecular mechanisms of the circadian system have been conserved between insects and mam- 
Circadian clocks

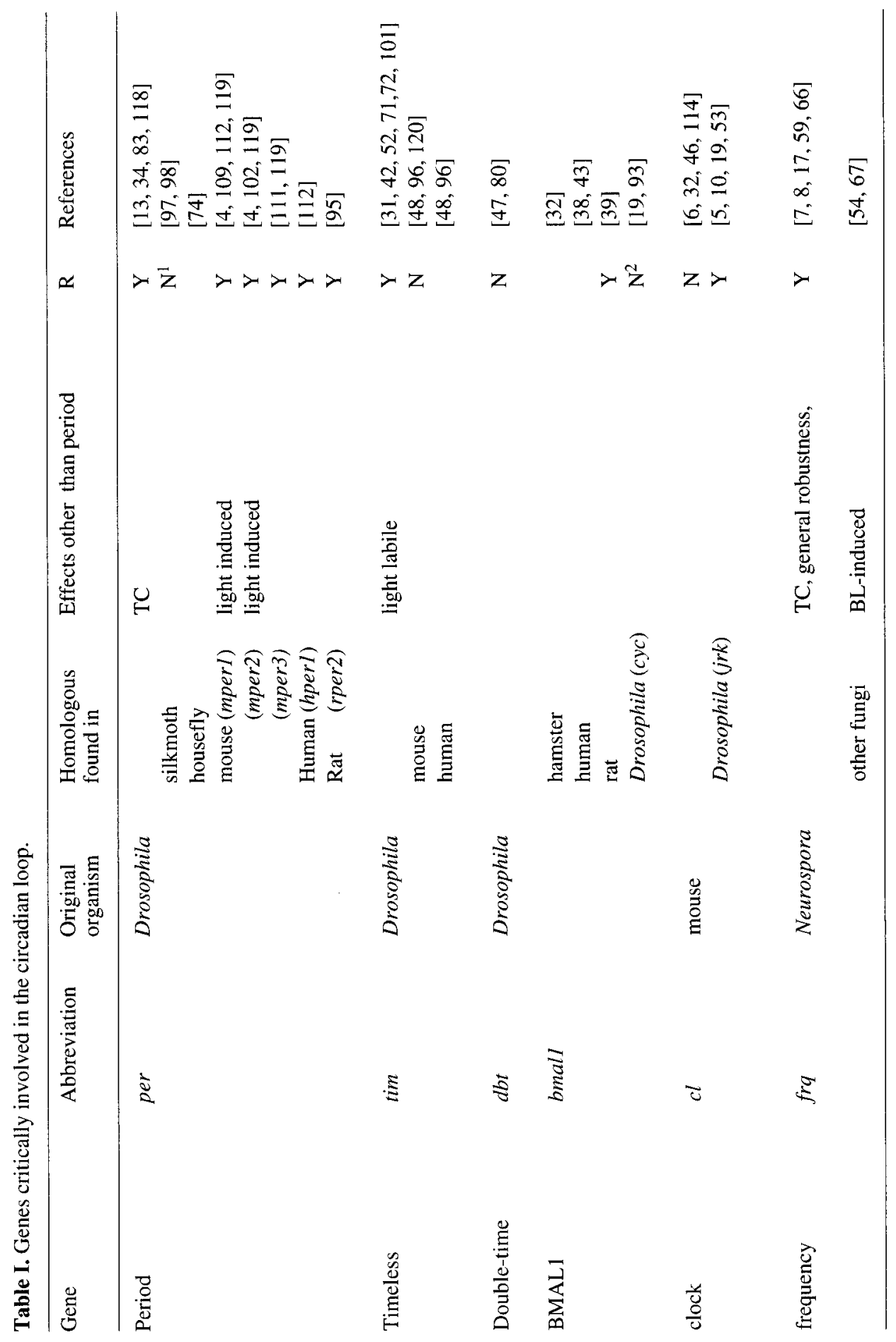




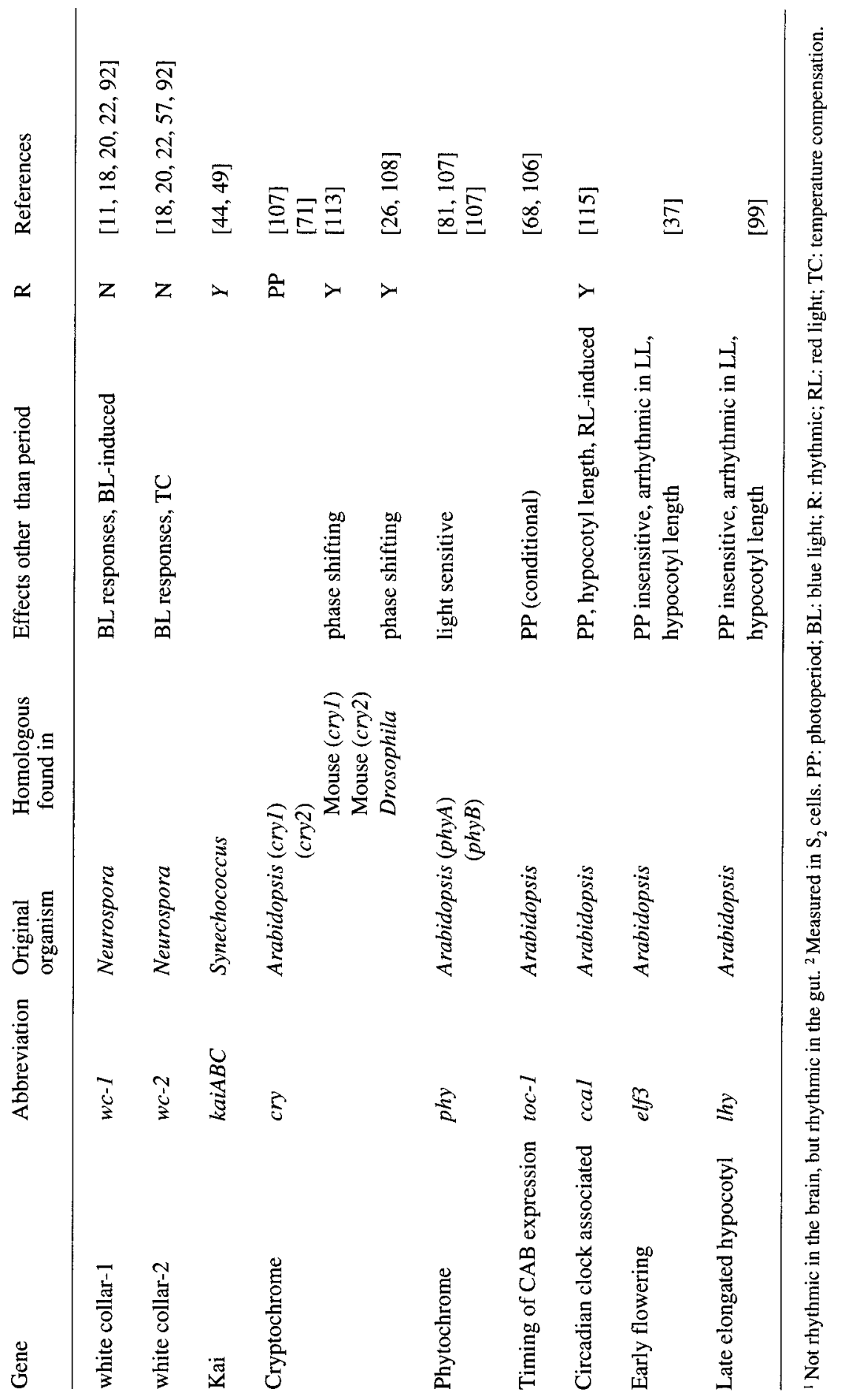


mals. Table I summarizes those genes that led to the full description of the molecular circadian loop in animals as well as those which are candidates for the completion of the circadian loop in micro-organisms and higher plants. First insights into the function of clock genes came from structural similarities (table $I I$ ). The PAS domain (named after the three Drosophila genes PER, ARNT, SIM), which mediates protein-protein interaction, was one of the first common elements recognized [18]. Furthermore, DNA-binding domains and sequences controlling cytoplasmatic or nuclear localization (CLS and NLS) indicate the involvement of heterodimers that are translocated to the nucleus at some part of the circadian cycle to control transcription.

\subsection{The current models}

The detailed model for the molecular circadian oscillator in animals (figure $2 A$ ) is based on two pairs of heterodimers.
BMAL1/CLOCK constitutes the transcriptional activator of the per and tim promoter. Their products, PER and TIM, also form a heterodimer, necessary for their translocation to the nucleus and for inhibition of their transcription via interaction with BMAL1/ CLOCK. Thus, the function of clock genes, described so far, is to control transcription. Most recently, it has been shown how an output rhythm in the mammalian $\mathrm{SCN}$ is controlled by this autoregulating negative feedback loop [45]. The promoter of the vasopressin gene, is also activated by the BMAL1/CLOCK complex (again via an Ebox) and is, thus, controlled in the same way as the clock components themselves. An important aspect of the circadian regulation of vasopressin is the fact that the vasopressin promoter and its expressed peptide do not constitute a negative feedback and are, thus, clearly downstream of the mechanism that generates the circadian rhythmicity. Based on the vasopressin model, it will be interesting to see how the circadian clock can control different output rhythms that do not oscillate in phase. Phase specificity may be

Table II. Structural comparison between clock genes.

\begin{tabular}{|c|c|c|c|c|c|c|c|}
\hline Gene & NLS & CLS & PAS & LOV & $\begin{array}{c}\text { DNA } \\
\text { bnd }\end{array}$ & Other structural features & References \\
\hline per & - & - & - & & & TG repeat & {$[13,83,94]$} \\
\hline tim & - & - & & & & & [94] \\
\hline$d b t$ & & & & & & casein kinase I $\varepsilon$ homologue & {$[47]$} \\
\hline bmall & & & • & & • & & {$[38,43]$} \\
\hline clock & & & & & - & Q-rich region & {$[6,19,32]$} \\
\hline frq & - & & & & & & [63] \\
\hline$w c-1$ & & & $\bullet$ & - & - & Q-rich region & {$[11,41]$} \\
\hline$w c-2$ & & & $\bullet$ & & - & TG repeat & {$[57]$} \\
\hline kaiABC & & & & & & & {$[44]$} \\
\hline cry & & & & & & FAD and tetrapyrrole bnd & {$[55,64]$} \\
\hline phy & & & - & & & tetrapyrrole bnd & {$[18,81]$} \\
\hline ccal & & & & & • & MYB homology & {$[115]$} \\
\hline lhy & & & & & & MYB homology & [99] \\
\hline
\end{tabular}

For some of these structural motifs, function is inferred by sequence; for others it has been experimentally demonstrated. NLS, nuclear localization signal; CLS, cytoplasmic localization signal; PAS, PAS domain; LOV, LOV (light oxygen voltage) domain; DNA bnd, DNA binding domain. 
A

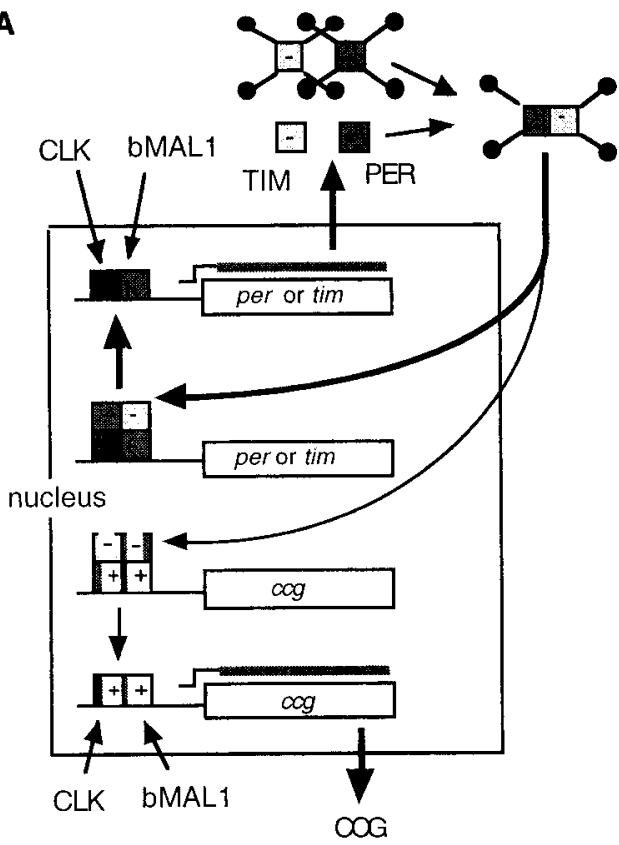

B

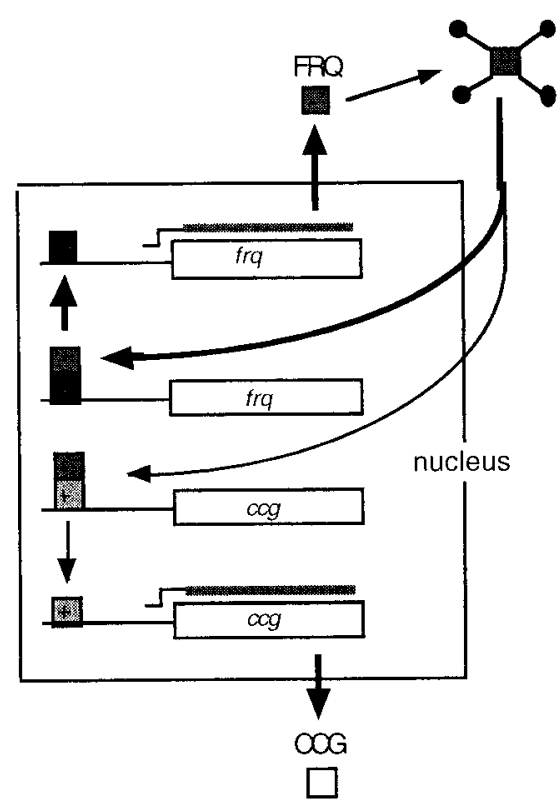

Figure 2. Transcription-based circadian feedback loops. A) A feedback loop has been described that is conserved from insects to mammals. Positive activators are CLOCK and BMAL1, which turn on per, tim or $c c g$ (clock controlled gene) expression. CLOCK/BMAL1 transcription is down-regulated by PER and TIM heterodimers, which are phosphorylated ( ) as part of a post-translational modification programme. Thus, an autoregulating feedback loop is constructed. B) A similar feedback loop has been described in the fungus Neurospora crassa. An as yet unidentified positive acting transcription factor ( $⿴$ ) (likely candidates are white collar proteins) is down-regulated by FRQ. FRQ is increasingly phosphorylated over time, as is PER in Drosophila.

achieved by further transcriptional elements that are activated at other circadian phases. In mammals, this could involve different per genes (mPerl and mPer2) which oscillate out of phase by $4 \mathrm{~h}$ [4]. There are, of course, many other scenarios by which output rhythms could be regulated at different circadian times. For example, all output rhythms so far described in the marine alga Gonyaulax, are controlled at the translational level [86] with a constitutive expression of the respective RNAs. Another possibility is the existence of 'slave oscillators', a concept that was first advocated by Pittendrigh for the eclosion rhythm in
Drosophila [76]. A clock-driven feedback loop involving an RNA binding protein was found in Arabidopsis [35], which can be regarded as a 'slave' to the circadian feedback loop. It could act as a gear in the circadian pathway determining a specific phase of the output.

Although the basic molecular mechanisms of the circadian loop in animals involve the same elements, there are several interspecific differences. The mammalian per RNAs peak during the day phase $[4,45,104,109,112]$, but they reach their maxima during the night in Drosophila [34, 
65]. In the fly, tim mRNA levels cycle [ 42 , 101], while they are constitutive in the mouse $[96,120]$. CLOCK is weakly rhythmic in flies but it is constitutive in the mouse [53]. BMAL1 is robustly rhythmic in the rat SCN [39] but is constitutive in Drosophila $\mathrm{S}_{2}$ cells in culture [19]. Thus, in mammals and in flies both the inhibitory and the activating heterodimers are rhythmic (rhythmicity of the functional element, the heterodimer, requires only one rhythmic partner). In mammals, BMAL1/CLOCK is rhythmic owing to the rhythmicity of BMAL1, in flies owing to the cycling of CLOCK. In mammals, PER/TIM is rhythmic owing to PER and in flies owing to both. These statements, of course, rely on the demonstration that rhythmicity of RNA also corresponds to rhythmicity of protein, which has yet to be shown for some of the components. But what makes the activating elements rhythmic? In Drosophila, CLOCK is absent in $\operatorname{tim}^{\circ}$ and per ${ }^{0}$ flies [53], thus constituting another possible feedback loop, while this interaction has not yet been shown in mammals.

Unlike in animals, the details of the transcriptional feedback loop have not been formally identified in Neurospora, though several good candidates exist (figure $2 B$ ). The striking conservation of elements between insects and mammals apparently does not extend to fungi, which raises the important question of analogy versus homology among the circadian systems across different phyla. Will the strategies that divergent organisms developed be similar, or will there be important differences? What specific biochemi$\mathrm{cal} / \mathrm{metabolic}$ mechanisms will be adopted to accommodate species-specific needs according to life cycle, spatial and temporal niche?

\subsection{Shedding light on the clock}

The endogenous generation of circadian rhythmicity is one of the important qualities of circadian systems. Synchronization to the 24-h cycle of the environment is another [88]. Several experiments over the last few years have addressed the molecular mechanism of light entrainment. In some cases, the distinction between oscillator and light input pathway is difficult to make. The mouse perl promoter, which has kinetics reminiscent of an oscillator component, contains light regulative elements $[4,104]$ and is induced by light similar to immediate early genes [113]. Mouse per 2 is also lightinducible, but the kinetics are much slower [4, 104]. Light regulation of the per promoter has not been shown in Drosophila, where photic entrainment is mediated via a rapid light-dependent degradation of TIM, thereby, also destabilizing PER $[42,73]$. The differences in temporal expression of clock genes (see section 2.4 ) reflect the differences in regulation by light.

The rapid light induction of the mammalian perl gene is analogous to the rapid induction of frq mRNA after exposure to light [17]. In Neurospora, almost all light responses are induced by blue light. Two sets of mutants, white collar-1 and white collar-2 (wc-1 and wc-2) [20] lack all characterized responses to blue light, including circadian entrainment [92]. Thus, it is conceivable that a single, discrete photoreceptor system is responsible for light reception in Neurospora. The white collar mutants are arhythmic in constant conditions, even following synchronization with a temperature pulse [18]. Both WC-proteins are DNAbinding transcription factors responsible for different aspects of positive induction in light responses $[11,57]$, including frq expression [18]. The absence of WC-1 impairs light induction of both $f r q$ and itself (thus, $w c-1$ transcription is positively autoregulated). In the absence of WC-2, $w c-1$ is not light-inducible but frq is, however, with altered baseline and saturation levels [18]. Recently, a wc-2 allele was described with an altered period and defective temperature compensation (Colette M., Dunlap J., pers. comm.). One interpretation 
of the white collar findings is that they are oscillator components [22]. They could, however, also be part of the circadian light input pathway and still lead to arhythmicity of the oscillator (see section 3.1).

In higher plants, phytochromes had long been candidates for circadian photoreceptors [62] but they could account only for part of the circadian light responses [70]. In algae, for example, two independent light inputs with different spectral sensitivities have opposite effects on the circadian clock [84]. The identification of a class of blue light-sensitive receptors in plants, the cryptochromes, led to discoveries well beyond the plant kingdom. Cryptochrome (cry) is homologous (by sequence) to the DNA repair enzyme DNA-photolyase, but lacks DNA-repair function. Its role in light reception was first discovered in connection with hypocotyl elongation [2]. Cryptochromes are flavin-binding, redox-sensitive, soluble proteins $[1,56]$. Loss of either of the cryptochrome genes cryl or cry 2 in Arabidopsis results in period changes of the free-running rhythms in constant blue light. Similar to the phytochrome mutant phyA, cryl exhibits a longer period at low blue light fluences compared to wild-type, consistent with the physical association of phyA and cryl [3]. Period is less affected in both $p h y B$ and cry 2 [107] suggesting different mechanism than for the responses via phyA and cryl.

Recently, homologues of the DNA photolyase and plant cryptochrome family have been found in insects $[26,108]$ and mammals, including humans [40, 113], and it has been postulated that they constitute a conserved type of circadian photoreceptor across several phyla. However, the story is complicated [60]. Unlike PER and TIM, Drosophila cry is considered to be an element of the circadian light transduction pathway that is under the control of the circadian oscillator [26]. Locomotor activity as well as tim and per expression in the lateral neurons, the circadian pacemakers in the Drosophila [36] brain, are rhythmic in $c r y^{b}$ mutants [108]. In contrast, when total head extracts are analysed for per and tim or when their expression is recorded from whole flies via a bioluminescence reporter gene [78], they are arhythmic [108]. Besides the lateral neurons, circadian oscillators are present throughout the entire fly [79] and these appear to become arhythmic in the cry mutant. Although biochemical photoreception remains to be demonstrated for the animal cryptochromes, cry plays some important role in circadian light reception. Its overexpression results in stronger responses to brief light pulses compared to wild-type, while these responses are absent in cry mutants [26]. The activity rhythm of the mutant, however, remains entrainable to light/dark cycles, maybe via feed back from light/dark-driven activity (Rosbash, pers. comm.). These results also substantiate that the Drosophila activity rhythm is controlled primarily by the lateral neurons [36] and not by any of the numerous other oscillators [79].

As in Arabidopsis, two photolyase/cryptochrome homologues were found in mice and humans, cryl and $c r y 2[40,113] . m C r y l$ expression in the mouse $\mathrm{SCN}$ is circadian. Mouse strains lacking $m C r y 2$ are still highly sensitive for phase shifting by light pulses and show altered periods in the circadian activity rhythm [113]. It had already been shown in mammals that circadian entrainment was transduced through the eyes, but as in actively swimming algae - not by the photoreceptors used for spatial orientation [88]. The finding in mammals is based on eliminating the known ocular receptor types by molecular, cell-specific methods without losing the ability of the circadian system to respond to light (measured both for phase shifting and melatonin suppression) $[28,61]$. Thus, due to the redundancy in circadian photic input, the direct involvement of a gene product as a receptor has to be tested using strains as genetic backgrounds that are already impaired in other receptor candidates. 


\section{RECONSTRUCTION}

\subsection{A complicated assignment}

Like many other functions in biology, circadian systems can be regarded as complex pathways, integrating exogenous and endogenous information and regulating cellular and systemic processes accordingly. At their sensory end, information about the cyclic environment is received and transduced to the mechanisms that produce the circadian rhythmicity which will then control the different output rhythms of the organism. This pathway may involve feedback not only within the oscillator but also in the inputs and outputs. Furthermore, inputs themselves can be under circadian control $[26,89]$ and outputs may feed back to the oscillator [87]. Due to the complexity of this pathway, all elements involved could theoretically be rhythmic as well as produce arhythmicity when their function is destroyed (e.g. by mutation of a gene), making the assignment of clock genes and their products within the circadian pathway difficult. In addition, physiological experiments have shown that single cells can contain more than one circadian oscillator [86], so that mutations of genes that produce key elements within one of the oscillators may not necessarily lead to an arhythmic phenotype.

We have shown theoretically that elements of input pathways can comply with all of the criteria also used to characterize elements of the oscillator [90]. When different properties are assigned to an input element in a mathematical model (thereby simulating alleles of a gene involved in signal transduction to the circadian oscillator as well as their overproduction and induction), the resulting rhythm adopts different periods, becomes arhythmic, or responds with phase shifts (see section 2.2).

\subsection{Combining old and new}

Free-running rhythms are the most conspicuous trait of all circadian clocks and they, therefore, have been predominantly used to find out whether genes are involved in circadian mechanisms. They are, however, artefacts of laboratory experiments and do not reflect the reality which was responsible for the evolution of circadian clocks. A majority of the circadian rules that have been developed by physiological research deal with the behaviour of circadian systems under zeitgeber conditions [ 9 , $68,77]$ and help us understand how endogenous rhythms are entrained (rather than synchronized by being driven) in a very systematic way into the rhythmic structure of the environment. The interactions of the molecular oscillator components will eventually have to explain all the characteristic features which have been described in detail by physiological research (including the more 'esoteric' features such as after-effects, splitting or internal desynchronization [9, 77, 86]). Conversely, the physiological methods and protocols can be used to elucidate the role and function of the molecular components. Although all circadian systems strongly respond to light signals, they can also be entrained by non-photic stimuli. These can also be an important tool in probing the function of the different molecular components.

We have addressed the difficulties shown in our theoretical model, described above, experimentally using the Neurospora model system. In a series of experiments [68], we were able to show that Neurospora strains that are impaired or non-functional for FRQ retain qualities characteristic for circadian systems. Namely, all Neurospora period mutant $f r q$ strains, as well as those deficient for FRQ protein (e.g. $f r q^{9}$, which cannot produce functional FRQ), are entrainable by temperature cycles. During this temperature entrainment of spore formation, $f r q^{9}$ mRNA remains arhythmic at high levels. When temperature cycles of different periods are applied, the different strains (including $f r q^{9}$ ) show a systematic range of phase angles, typical for intact circadian clocks. FRQ-less strains are, however, not entrain- 
able by light cycles, and all other rhythmic frq strains appear to be driven by light rather than being entrained via the circadian mechanisms of a running clock. Their rhythms are locked to 'lights off', developing the first conidial band after a fixed but strainspecific lag, regardless of zeitgeber period. These results indicate that the role of FRQ in the Neurospora clock is associated with a circadianly regulated light input pathway. Without FRQ, the clock cannot function properly. FRQ provides the circadian range of the period and a robustness to the oscillator necessary for self-sustainment and to drive output rhythms. These experiments exemplify the importance of investigating the molecular elements (both RNA and protein) under the different entrainment protocols developed for the characterization of circadian systems, using both light and other, non-photic zeitgebers.

\section{REFERENCES}

[1] Ahmad M., Cashmore A.R., HY4 gene of $A$. thaliana encodes a protein with characteristics of a blue-light photoreceptor, Nature 366 (1993) 162-166.

[2] Ahmad M., Cashmore A.R., Seeing blue: the discovery of cryptochrome, Plant Mol. Biol. 30 (1996) 851-861.

[3] Ahmad M., Cashmore A.R., The CRYl blue light photoreceptor of Arabidopsis interacts with phytochrome A in vitro, Mol. Cell 1 (1998) 939-948.

[4] Albrecht U., Sun Z.S., Lee C.C., Eichele G., McLean V.M., A differential response of two putative mammalian circadian regulators, mper 1 and mper2, to light, Cell 91 (1997) 1055-1064.

[5] Allada R., White N.E., So W.V., Hall J.C., Rosbash M., A mutant Drosophila homolog of mammalian Clock disrupts circadian rhythms and transcription of period and timeless, Cell 93 (1998) 791-804.

[6] Antoch M.P., Song E.-J., Chang A.-M., Hotz Vitaterna M., Zhao Y., Wisbacher L.D., Sangoram A.M., King D.P., Pinto L.H., Takahashi J.S., Functional identification of the mouse circadian clock gene by transgenic BAC rescue, Cell 89 (1997) 655-667.

[7] Aronson B.D., Johnson K.A., Loros J.J., Dunlap J.C., Negative feedback defining a circadian clock: autoregulation of the clock gene frequency, Science 263 (1994) 1578-1584.
[8] Aronson B.D., Johnson K.A., Dunlap J.C., The circadian clock locus frequency: a single ORF defines period length and temperature compensation, Proc. Natl. Acad. Sci., USA 91 (1994) 7683-7687.

[9] Aschoff J. (Ed.), Biological Rhythms, Plenum Press, New York, 1981.

[10] Bae K., Lee C., Sidote D., Chuang K.Y., Edery I., Circadian regulation of a Drosophila homolog of the mammalian Clock gene: PER and TIM function as positive regulators, Mol. Cell Biol. 18 (1998) 6142-6151.

[11] Ballario P., Vittorioso P., Magrelli A., Talora C., Cabibbo A., Macino G., White collar-1, a central regulator of blue light responses in $\mathrm{Neu}$ rospora, is a zinc finger protein, EMBO J. 15 (1996) 1650-7.

[12] Balsalobre A., Damiola F., Schibler U., A serum shock induces gene expression in mammalian tissue culture cells, Cell 93 (1998) 929-937.

[13] Bargiello T.A., Jackson F.R., Young M.W., Restoration of circadian behavioural rhythms by gene transfer in Drosophila, Nature 312 (1984) 752-754.

[14] Bruce V.G., Mutants of the biological clock in Chlamydomonas reinhardi, Genetics 70 (1976) 537-548.

[15] Cahill G.M., Besharse J.C., Circadian clock functions localized in Xenopus retinal photoreceptors, Neuron 10 (1993) 573-577.

[16] Cheng Y., Hardin P.E., Drosophila photoreceptors contain an autonomous circadian oscillator that can function without period mRNA cycling, J. Neurosci. 18 (1998) 741-750.

[17] Crosthwaite S.K., Loros J.J., Dunlap J.C., Lightinduced resetting of a circadian clock is mediated by a rapid increase in frequency transcript, Cell 81 (1995) 1003-1012.

[18] Crosthwaite S.K., Dunlap J.C., Loros J.J., Neurospora $w c-1$ and $w c-2$ : Transcription, photoresponses, and the origin of circadian rhythmicity, Science 276 (1997) 763-769.

[19] Darlington T.K., Wager-Smith K., Ceriani M.F., Staknis D., Gekakis N., Steeves T.D.L., Weitz C.J., Takahashi J.S., Kay S.A., Closing the circadian loop: CLOCK-induced transcription of its own inhibitors per and tim, Science 280 (1998) 1599-1603.

[20] Degli-Innocenti F., Russo V.E., Isolation of new white collar mutants of Neurospora crassa and studies on their behaviour in the blue lightinduced formation of protoperithecia, J. Bacteriol. 159 (1984) 757-761.

[21] Dembinska M.E., Stanewsky R., Hall J.C., Rosbash M., Circadian cycling of a PERIOD$\beta$-galactosidase fusion protein in Drosophila: evidence for cyclical degradation, J. Biol. Rhythms 12 (1997) 157-172.

[22] Dunlap J.C., Molecular bases for circadian clocks, Cell 96 (1999) 271-290. 
[23] Edery I., Zwiebel L.J., Dembinska M.E., Rosbash M., Temporal phosphorylation of the Drosophila period protein, Proc. Natl. Acad. Sci. 91 (1994) 2260-2264.

[24] Edery I., Rutila J.E., Rosbash M., Phase shifting of the circadian clock by induction of the Drosophila period protein, Science 263 (1994) 237-240.

[25] Edmunds L.N., Jr, Cellular and Molecular Bases of Biological Clocks: Models and Mechanisms of Circadian Time Keeping, Springer, New York Heidelberg, 1988.

[26] Emery P., So W.V., Kaneko M., Hall J.C., Rosbash M., CRY, a Drosophila clock and lightregulated cryptochrome, is a major contributor to circadian rhythm resetting and photosensitivity, Cell 95 (1998) 669-679.

[27] Feldman J.F., Hoyle M.N., Isolation of circadian clock mutants of Neurospora crassa, Genetics 75 (1973) 605-613.

[28] Freedman M.S., Lucas R.J., Soni B., Schantz M.V., Munoz M., David-Gray Z.K., Foster R.G., Nonrod, non-cone ocular photoreceptors regulate the mammalian circadian behaviour, Science (1999) 502-505.

[29] Frisch B., Hardin P.E., Hamblen-Coyle M.J., Rosbash M., Hall J., A promoterless period gene mediates behavioral rhythmicity and cyclical per expression in a restricted subset of the Drosophila nervous system, Neuron 12 (1994) 555-570.

[30] Garceau N.Y., Liu Y., Loros J.J., Dunlap J., Alternative initiation of translation and time specific phosphorylation yield multiple forms of the essential clock protein FREQUENCY, Cell 89 (1997) 469-476.

[31] Gekakis N., Saez L., Delahaye-Brown A.-M., Myers M.P., Sehgal A., Young M.W., Weitz C.J., Isolation of timeless by PER Protein Interaction: Defective interaction between timeless protein and long-period mutant $\mathrm{PER}^{\mathrm{L}}$, Science 270 (1995) 811-815.

[32] Gekakis N., Staknis D., Nguyen H.B., Davis F.C., Wilsbacher L.D., King D.P., Takahashi J.S., Weitz C.J., Role of the CLOCK protein in the mammalian circadian mechanism, Science 280 (1998) 1564-1569.

[33] Hao H., Allen D.L., Hardin P.E., A circadian enhancer mediates PER-dependent mRNA cycling in Drosophila melanogaster, Mol. Cell Biol. 17 (1997) 3687-3693.

[34] Hardin P.E., Hall J.C., Rosbash M., Feedback of the Drosophila period gene product on circadian cycling of its messenger RNA levels, Nature 343 (1990) 536-540.

[35] Heintzen C., Nater M., Apel K., Staiger D., AtGRP7, a nuclear RNA-binding protein as a component of a circadian regulated negative feedback loop in Arabidopsis thaliana, Proc. Natl. Acad. Sci., USA 95 (1997) 8515-8520.
[36] Helfrich-Förster C., Drosophila rhythms: from brain to behaviour, Semin. Cell Dev. Biol. 7 (1996) 791-802.

[37] Hicks K.A., Millar A.J., Carré I.A., Somers D.E., Straume M., Meeks-Wagner R., Kay S.A., Conditional circadian dysfuncion of the Arabidopsis early-flowering 3 mutant, Science 274 (1996) 790-792.

[38] Hogenesch J.B., Chan W.K., Jackiw V.H., Brown R.C., Gu Y.Z., Pray-Grant M., Perdew G.H., Bradfield C.A., Characterization of a subset of the basic-helix-loop-helix-PAS superfamily that interacts with components of the dioxin signaling pathway, J. Biol. Chem. 272 (1997) 8581-8593.

[39] Honma S., Ikeda M., Abe H., Tanahashi Y., Namihira M., Honma K., Nomura M., Circadian oscillation of BMAL1, a partner of a mammalian clock gene Clock, in rat suprachiasmatic nucleus, Biochem. Biophys. Res. Commun. 250 (1998) 83-87.

[40] Hsu D.S., Zhao X., Zhao S., Kazantsev A., Wang R.P., Todo T., Wei Y.F., Sancar A., Putative human blue-light photoreceptors hCRY 1 and hCRY2 are flavoproteins, Biochemistry 35 (1996) 13871-13877.

[41] Huala E., Oeller P.W., Liscum E., Briggs W.R., Han I.-S., Arabidopsis NPH1: a protein kinase with a putative redox-sensing domain, Science 278 (1997) 2120-2123.

[42] Hunter-Ensor M., Ousley A., Sehgal A., Regulation of the Drosophila protein timeless suggests a mechanism for resetting the circadian clock by light, Cell 84 (1996) 677-85.

[43] Ikeda M., Nomura M., cDNA cloning and tissuespecific expression of a novel basic helix-loophelix/PAS protein (BMAL1) and identification of alternatively spliced variants with alternative translation initiation site usage. Biochem. Biophys. Res. Commun. 233 (1997) 258-264.

[44] Ishiura M., Kutsuna S., Aoki S., Iwasaki H., Andersson C.R., Tanabe A., Golden S.S., Johnson C.H., Kondo T., Expression of a gene cluster kaiABC as a circadian feedback process in cyanobacteria, Science 281 (1998) 1519-1523.

[45] Jin X., Shearman L.P., Weaver D.R., Zylka M.J., DeVries G.J., Reppert S.M., A molecular mechanism regulating rhythmic output from the suprachiasmatic circadian clock, Cell 96 (1998) 57-68.

[46] King D.P., Zhao Y., Sangoram A.M., Wilsbacher L.D., Tanaka M., Antoch M.P., Steeves T.D.L., Hotz Vitaterna M., Kornhauser J.M., Lowrey P.L., Turek F.W., Takahashi J.S., Positional cloning of the mouse circadian clock gene, Cell 89 (1997) 64l-653.

[47] Kloss B., Price J.L., Saez L., Blau J., Rothenfluh A., Wesley C.S., Young M.W., The Drosophila clock gene double-time encodes a protein closely related to human casein kinase epsilon, Cell 94 (1998) 97-107. 
[48] Koike N., Hida A., Numano R., Hirose M., Sakaki Y., Tei H., Identification of the mammalian homologues of the Drosophila timeless gene, Timeless1, FEBS Lett. 441 (1998) 427-431.

[49] Kondo T., Tsinoremas N.F., Golden S.S., Johnson C.H., Kutsuna S., Ishiura M., Circadian clock mutants of cyanobacteria, Science 266 (1994) 1233-1236.

[50] Konopka R., Benzer S., Clock mutants of Drosophila melanogaster, Proc. Natl. Acad. Sci. USA 68 (1971) 2112-2116.

[51] Lakin-Thomas P.L., Choline depletion, frq mutations, and temperature compensation of the circadian rhythm in Neurospora crassa, J. Biol. Rhythms 13 (1998) 268-277.

[52] Lee C., Parikh V., Itsukaichi T., Bea K., Edery I., Resetting the Drosophila clock by photic regulation of PER and PER-TIM complex, Science 271 (1996) 1740-1744.

[53] Lee C., Bae K., Edery I., The Drosophila CLOCK protein undergoes daily thythms in abundance, phosphorylation, and interactions with PER-TIM complex, Neuron 21 (1998) 857-867.

[54] Lewis M.T., Morgan L.W., Feldman J.F., Analysis of frequency (frq) clock gene homologs: evidence for a helix-turn-helix transcription factor, Mol. Gen. Genet. 253 (1997) 401-414.

[55] Lin C., Robertson D.E., Ahmad M., Raibekas A.A., Schuman-Jorns M., Dutton P.L., Cashmore A.R., Association of flavin adenine dinucleotide with the Arabidopsis blue light receptor CRY1, Science 269 (1995) 968-970.

[56] Lin C., Ahmad M., Cashmore A.R., Arabidopsis cryptochrome $I$ is a soluble protein mediating blue light-dependent regulation of plant growth and development, Plant J. 10 (1996) 893-902.

[57] Linden H., Macino G., White collar 2, a partner in blue-light signal transduction, controlling expression of light-regulated genes in $\mathrm{Neu}$ rospora crassa, EMBO J. 16 (1997) 98-109.

[58] Liu Y., Merrow M., Loros J.L., Dunlap J.C., How temperature changes reset a circadian oscillator, Science 281 (1998) 825-829.

[59] Loros J.J., Richman A., Feldman J.F., A recessive circadian clock mutation at the frq locus of Neurospora crassa, Genetics 114 (1986) 1095-1110.

[60] Lucas R.J., Foster R.G., Photoentrainment in mammals: a role for cryptochrome, J. Biol. Rhythms 14 (1998) 4-10.

[61] Lucas R.J., Freedman M.S., Munoz M., GarciaFernandez J., Foster R.G., Non-rod, non-cone ocular photoreceptors regulate the mammalian pineal, Science (1999) 505-507.

[62] Lumsden P.J., Circadian rhythms and phytochrome, Annu. Rev. Plant Physiol. Mol. Biol. 42 (1991) 351-371.
[63] Luo C., Loros J.J., Dunlap J.C., Nuclear localization is required for function of the essential clock protein FRQ, EMBO J. 17 (1998) 1228-1235.

[64] Malhotra K., Kim S.T., Batschauer A., Dawut L., Sancar A., Putative blue-light photoreceptors in Arabidopsis thaliana and Synapis alba with a high degree of sequence homology to DNA photolyase contain the two photolyase cofactors but lack DNA repair activity, Biochemistry 34 (1995) 6892-6899.

[65] Marrus S.B., Zeng H., Rosbash M., Effect of constant light and circadian entrainment of per flies: evidence for light mediated delay of the negative feedback loop in Drosophila, EMBO J. 15 (1996) 6877-6886.

[66] McClung C.R., Fox B.A., Dunlap J.C., The Neurospora clock gene frequency shares a sequence element with the Drosophila clock gene period, Nature 339 (1989) 558-562.

[67] Merrow M.W., Dunlap J.C., Intergeneric complementation of a circadian rhythmicity defect: phylogenetic conservation of structure and function of the clock gene frequency, EMBO J. 13 (1994) 2257-2266.

[68] Merrow M., Roenneberg T., Assignment of circadian function for the Neurospora clock gene frequency, Nature (1999) in press.

[69] Millar A.J., Carré I.A., Strayer C.A., Chua N.-H., Kay S.A., Circadian clock mutants in Arabidopsis identified by luciferase imaging, Science 267 (1995) 1161-1163.

[70] Millar A.J., Straumer M., Chorry J., Chua N.-H., Kay S.A., The regulation of circadian period by phototransduction pathways in Arabidopsis, Science 267 (1995) 1163-1166.

[71] Miyamoto Y., Sancar A., Vitamin B2-based blue-light photoreceptors in the retinohypothalamic tract as the photoactive pigments for setting the circadian clock in mammals, Proc. Natl. Acad. Sci. USA 95 (1998) 6097-6102.

[72] Myers M.P., Wagner-Smith K., Wesley C.S., Young M.W., Sehgal A., Positional cloning and sequence analysis of the Drosophila clock gene timeless, Science 270 (1995) 805-808.

[73] Myers M., Wagersmith K., Rothenfluhhilfiker A., Young M., Light induced degeneration of timeless and entrainment of the Drosophila circadian clock, Science 271 (1996) 1736-1740.

[74] Nielsen J., Peixoto A.A., Piccin A., Costa R., Kyriacou C.P., Chalmers D., Big flies, small repeats: the 'Thr-Gly' region of the period gene in Diptera, Mol. Biol. Evol. 11 (1994) 839-853.

[75] Pickard G., Tang W., Pineal photoreceptors rhythmically secrete melatonin, Neurosci. Lett. 171 (1994) 109-112.

[76] Pittendrigh C.S., Circadian rhythms and the circadian organization of living systems, Cold Spring Harbor Symp. Quant. Biol. 25 (1960) 159-184. 
[77] Pittendrigh C.S., Daan S., A functional analysis of circadian pacemakers in noctural rodents: IV. Entrainment: Pacemaker as clock, J. Comp. Physiol. A 106 (1976) 291-331.

[78] Plautz J.D., Staume M., Stanewsky R., Jamison C.F., Brandes C., Dowse H.B., Hall J.C., Kay S.A., Quantitative analysis of Drosophila period gene transcription in living animals, J. Biol. Rhythms 12 (1997) 204-217.

[79] Plautz J.D., Kaneko M., Hall J.C., Kay S.A., Independent photoreceptive circadian clocks throughout Drosophila, Science 278 (1997) 1632-1635.

[80] Price J.L., Blau J., Rothenfluh A., Abodeely M., Kloss B., Young M.W., double-time is a novel Drosophila clock gene that regulates PERIOD protein accumulation, Cell 94 (1998) 83-95.

[81] Quail P.H., Boylan M.T., Parks B.M., Short T.W., Xo Y., Wagner D., Phytochromes: photosensory perception and signal transduction, Science 268 (1995) 675-680.

[82] Ralph M.R., Menaker M., A mutation of the circadian system in golden hamsters, Science 241 (1988) 1225-1227.

[83] Reddy P., Zehring W.A., Wheeler D.A., Pirrotta V., Hadfield C., Hall J.C., Rosbash M., Molecular analysis of the period locus in Drosophila melanogaster and identification of a transcript involved in biological rhythms, Cell 38 (1984) 701-710.

[84] Roenneberg T., Hastings J.W., Two photoreceptors influence the circadian clock of a unicellular alga, Naturwissenschaften 75 (1988) 206-207.

[85] Roenneberg T., Morse D., Two circadian oscillators in one cell, Nature 362 (1993) 362-364.

[86] Roenneberg T., Mittag M., The circadian program of algae, Semin. Cell Dev. Biol. 7 (1996) 753-763.

[87] Roenneberg T., Rehman J., Nitrate, a nonphotic signal for the circadian system, FASEB J. 10 (1996) 1443-1447.

[88] Roenneberg T., Foster R.G., Twilight Times Light and the circadian system, Photochem. Photobiol. 66 (1997) 549-561.

[89] Roenneberg T., Deng T.-S., Photobiology of the Gonyaulax circadian system: I Different phase response curves for red and blue light, Planta 202 (1997) 494-501.

[90] Roenneberg T., Merrow M., Molecular circadian oscillators - an alternative hypothesis, J. Biol. Rhythms 13 (1998) 167-179.

[91] Roenneberg T., Rehman J. (Eds.), Survival in a Temporal World - The Circadian Program of the Marine Unicell Gonyaulax, University Press, Cambridge, 1998.

[92] Russo V.E., Blue light induces circadian thythms in the $b d$ mutant of Neurospora: double mutants $b d, w c-I$ and $b d, w c-2$ are blind, J. Photochem. Photobiol. B. 2 (1988) 59-65.
[93] Rutila J.E., Suri V., Le M., So M.V., Rosbash M., Hall J.C., CYCLE is a second bHLH-PAS clock protein essential for circadian rhythmicity and transcription of Drosophila period and timeless, Cell 93 (1998) 805-814.

[94] Saez L., Young M., Regulation of nuclear entry of the Drosophila clock proteins period and timeless, Neuron 17 (1996) 911-920.

[95] Sakamoto K., Nagase T., Fukui H., Horikawa K., Okada T., Tanaka H., Sato K., Miyake Y., Ohara O., Kako K., Ishida N., Multitissue circadian expression of rat period homolog ( $r$ Per2) mRNA is governed by the mammalian circadian clock, the suprachiasmatic nucleus in the brain, J. Biol. Chem. 273 (1998) 27039-27042.

[96] Sangoram A.M., Saez L., Antoch M.P., Gekakis N., Staknis D., Whiteley A., Freuchte E.M., Vitaterna M.H., Shimomura K., King D.P., Young M.W., Weitz C.J., Takahashi J.S., Mammalian circadian autoregulatory loop: a Timeless ortholog and mPerl interact and negatively regulate CLOCK-BMAL1-induced transcription, Neuron 21 (1998) 1101-1113.

[97] Sauman I., Reppert S.M., Circadian clock neurons in the silkmoth Antheraea pernyi: novel mechanisms of period protein regulation, Neuron (1996) 889-900.

[98] Sauman I., Tsai T., Roca A.L., Reppert-SM Period protein is necessary for circadian control of egg hatching behaviour in the silkmoth Antheraea pernyi, Neuron 17 (1996) 901-909.

[99] Schaffer R., Ramsay N., Samach A., Corden S. Putterill J., Carre I.A., Coupland G., The late elongated hypocotyl mutation of Arabidopsis disrupts circadian rhythms and the photoperiodic control of flowering, Cell 93 (1998) 1219-1229.

[100] Sehgal A., Price J.L., Man B., Young M.W., Loss of circadian behavioral rhythms and per RNA oscillations in the Drosophila mutant timeless, Science 263 (1994) 1603-1606.

[101] Sehgal A., Rothenfluh-Hilfiker A., HunterEnsor M., Cheng Y., Myers M.P., Young M.W. Rhythmic expression of timeless: a basis for promoting circadian cycles in period gene autoregulation, Science 270 (1995) 808-810.

[102] Shearman L.P., Zylka M.J., Weaver D.R., Kolakowski L.F., Reppert S.M., Two period homologs: circadian expression and photic regulation in the suprachiasmatic nuclei, Neuron 19 (1997) 1261-1269.

[103] Shen H.M., Watanabe M., Tomasiewicz H., Rutishauser U., Magnuson T., Glass J.D., Role of neural cell adhesion molecule and polysialic acid in mouse circadian clock function, J. Neurosci. 17 (1997) 5221-5229.

[104] Shigeyoshi Y., Taguchi K., Yamamoto S., Takekida S., Yan L., Tei H., Moriya T., Shibata S. Loros J., Dunlap J., C., Okamura H., Lightinduced resetting of a mammalian clock is associated with rapid induction of the mPerl transcript, Cell 9l (1997) 1043-1053. 
[105] So W.V., Rosbash M., Post-transcriptional regulation contributes to Drosophila clock gene mRNA cycling, EMBO J. 16 (1997) 7146-7155.

[106] Somers D.E., Webb A.A., Pearson M., Kay S.A., The short-period mutant, toc $1-1$, alters circadian clock regulation of multiple outputs throughout development in Arabidopsis thaliana, Development 125 (1998) 485-494.

[107] Somers D.E., Devlin P.F., Kay S.A., Phytochromes and cryptochromes in the entrainment of the Arabidopsis circadian clock, Science 282 (1998) 1488-1490.

[108] Stanewsky R., Kaneko M., Emery P., Beretta B., Wagner-Smith K., Kay S.A., Rosbash M., Hall J.C., The cry $^{b}$ mutation identifies cryptochrome as a circadian photoreceptor in Drosophila, Cell 95 (1998) 681-692.

[109] Sun Z.S., Albrecht U., Zhuchenko O., Bailey J., Eichele G., Lee C.C., RIGUI, a putative mammalian ortholog of the Drosophila period gene, Cell 90 (1997) 1003-1011.

[110] Sweeney B.M., Borgese M.B., A circadian rhythm in cell division in a prokaryote, the cyanobacterium Synechococcus WH7803, J. Phycol. 25 (1989) 183-186.

[111] Takumi T., Taguchi K., Miyake S., Sakakida Y., Takashima N., Matsubara C., Maebayashi Y., Okumura K., Takekida S., Yamamoto S., Yagita K., Yan L., Young M.W., Okamura H., A light-independent oscillatory gene $m P e r 3$ in mouse SCN and OVLT, EMBO J. 17 (1998) 4753-4759.

[112] Tei H., Okamura H., Shigeyoshi Y., Fukuhara C., Ozawa R., Hirose M., Sakaki Y., Circadian oscillation of a mammalian homologue of the Drosophila period gene, Nature 389 (1997) 512-516.
[113] Thresher R.J., Vitaterna M.H., Miyamoto Y., Kazantsev A., Hsu D.S., Petit C., Selby C.P., Dawut L., Smithies O., Takahashi J.S., Sancar A., Role of mouse cryptochrome blue-light photoreceptor in circadian photoresponses, Science 282 (1998) 1490-1494.

[114] Vitaterna M.H., King D.P., Chang A.-M., Kornhauser J.M., Lowrey P.L., McDonald J.D., Dove W.F., Pinto L.H., Turek F.W., Takahashi J.S., Mutagenesis and mapping of a mouse gene, Clock, essential for circadian behaviour, Science 264 (1994) 719-725.

[115] Wang Z.Y., Tobin E.M., Constitutive expression of the CIRCADIAN CLOCK ASSOCIATED 1 (CCAl) gene disrupts circadian rhythms and suppresses its own expression, Cell 93 (1998) 1207-1217.

[116] Young M.W., The molecular control of circadian behavioral rhythms and their entrainment in Drosophila, Annu. Rev. Biochem. 67 (1998) 135-152.

[117] Zeng H., Hardin P.E., Rosbash M., Constitutive overexpression of the Drosophila period protein inhibits period mRNA cycling, EMBO J. 13 (1994) 3590-3598.

[118] Zerr D.M., Hall J.C., Rosbash M., Siwicki K.K., Circadian fluctuations of period protein immunoreactivity in the CNS and the visual system of Drosophila, J. Neurosci. 8 (1990) 2749-2762.

[119] Zylka M.J., Shearman L.P., Weaver D.R., Reppert S.M., Three period homologs in mammals: differential light responses in the suprachiasmatic circadian clock and oscillating transcripts outside of brain, Neuron 20 (1998) 1103-1110.

[120] Zylka M.A., Shearman L.P., Levine J.D., Jin X., Weaver D.R., Reppert S.M., Molecular analysis of mammalian timeless, Neuron 21 (1998) 1115-1122. 